\title{
An Autopsy Case of Hypertrophic Cardiomyopathy with Pathological Findings Suggesting Chronic Myocarditis
}

\author{
Hiroaki Kawano, M.D., Sachio KawaI, M.D., \\ Takashi Nishijo, M.D., * Toshikazu ShIRAI, M.D.,*** \\ Yoshiaki INAGAKI, M.D., ${ }^{* * *}$ \\ and Ryozo OKaDA, M.D.
}

\begin{abstract}
SUMMARY
Myocardial fibrosis in patients with hypertrophic cardiomyopathy (HCM) may play an important role in the function and/or dimensions of the left ventricle. We present an autopsied case of HCM followed for 10 years. A 68-year-woman with HCM underwent trans-aortic myectomy of the interventricular septum in 1979. A significant amount of round cell infiltration, myocardial fibrosis and disarray were observed in the resected specimen. She experienced repeated admissions due to diabetes mellitus and congestive heart failure, and died of renal failure in 1989. An autopsy revealed extensive myocardial fibrosis and significant cell infiltration in the ventricular myocardium. The infiltrating cells were almost all lymphocytes, and the ratio of CD4 to CD8 was 3.8 . This ratio was different from that of typical viral myocarditis. This case suggests that there may be an undefined inflammatory process causing fibrosis in HCM, in addition to the ischemia due to intramural small coronary artery stenosis. (Jpn Heart J 35: 95-105, 1994)
\end{abstract}

Key words: Hypertrophic cardiomyopathy Myocarditis Lymphocyte subsets

\footnotetext{
LTHOUGH lymphocytic infiltration and inflammation are considered to 1 be among the potential causative factors for dilated cardiomyopathy, focal collection of mononuclear cells in the myocardium of patients with hypertrophic cardiomyopathy (HCMM) is recognized as a non-pathognomonic and incidental finding. ${ }^{\text {l) }}$

Myocardial fibrosis in $\mathrm{HCM}^{2,3)}$ could play an important role in the development of dilatation of the ventricle. ${ }^{4-11)}$ Among several hypotheses ${ }^{43)}$ concerning

From Research Laboratory for Cardiovascular Pathology, *Division of Cardiology, Department of Internal Medicine, **Department of Pathology, Juntendo University School of Medicine, Tokyo, and ***Third Department of Internal Medicine, University of Chiba, Chiba, Japan

Address for correspondence: Hiroaki Kawano, M.D., Research Laboratory for Cardiovascular Pathology, Juntendo University School of Medicine, 2-1-1 Hongo, Bunkyo-ku, Tokyo 113, Japan.

Received for publication October 8, 1993.

Accepted December 2, 1993.
} 
the etiology of myocardial fibrosis in HCM, intramural coronary artery sclerosis has become widely accepted. ${ }^{12,13)}$ However, other possible factors causing fibrosis were not extensively studied.

We treated a case of HCM which showed cell infiltration in a surgical biopsy specimen 10 years earlier, and broad myocardial fibrosis and cell infiltration at autopsy.

\section{Gase Report}

A 68-year-old Japanese female without personal or family history of any cardiac disease began to notice dyspnea and pretibial edema at the age of 39 years (1961). She experienced dyspnea on exertion, and consulted a family doctor in 1970. Subsequently, cardiomegaly and diabetes mellitus were diagnosed. She underwent medication and her condition ameliorated. Symptoms of congestive heart failure recurred, but she stopped taking medication. In 1976, she experienced severe orthopnea and was admitted to Chiba University Hospital. Chest $\mathrm{X}$-ray showed marked cardiomegaly (Figure 1A). Echocardiogram demonstrated asymmetrical septal hypertrophy and systolic anterior movement of the anterior leaflet of the mitral valve (Figure 2). She was diagnosed as having HCM with obstruction, and was treated with spironolactone and furosemide. She felt faintness in spite of medication, and was transferred to our hospital for surgery.

On admission her body temperature was $35.6^{\circ} \mathrm{C}$ and pulse rate was $75 /$ min. Blood pressure was 122/68 mmHg. On physiological examination, her height was $147.2 \mathrm{~cm}$ and her weight was $72.5 \mathrm{~kg}$. Heart sounds were regular; a Grade 4 systolic murmur was maximal at the left upper sternal border; an $S_{4}$ was present. Inspiratory crackles were heard at both lung bases. The liver was felt 2 $\mathrm{cm}$ in width. There was pretibial edema.

The hematocrit was $11.1 \%$ and the white-cell count was $6800 / \mathrm{mm}^{3}$. The erythrocyte segimentation rate was $14 \mathrm{~mm}$ per hour. The blood urea nitrogen was $20 \mathrm{mg} / \mathrm{d} l$, creatinine $1.5 \mathrm{mg} / \mathrm{d} l$, creatine phosphokinase $53 \mathrm{IU}$, glutamate oxaloacetate aminotransferase $28 \mathrm{IU} / l$, glutamate pyruvate aminotransferase 8 $\mathrm{IU} / l$, lactate dehydrogenase $480 \mathrm{IU} / l$, glucose $99 \mathrm{mg} / \mathrm{d} l$, total cholesterol 227 $\mathrm{mg} / \mathrm{d} l$, and triglycerides $109 \mathrm{mg} / \mathrm{d} l$. The sodium was $149 \mathrm{mEq} / l$, potassium 3.6 $\mathrm{mEq} / l$, and chloride $108 \mathrm{mEq} / l$.

Electrocardiogram (ECG) showed left ventricular hypertrophy. Right-sided and left-sided cardiac catheterization revealed a right atrial mean pressure of 12 $\mathrm{mmHg}$, and a right ventricular pressure of $70 / 10 \mathrm{mmHg}$; the pulmonary arterial pressure was $50 / 34 \mathrm{mmHg}$, with a mean pressure of $44 \mathrm{mmHg}$; the pulmonarycapillary wedge pressure was $24 \mathrm{mmHg}$; the left ventricular pressure was $232 / 20$ at the apex and $135 / 20 \mathrm{mmHg}$ at the outflow, and the aortic pressure was $130 /$ 


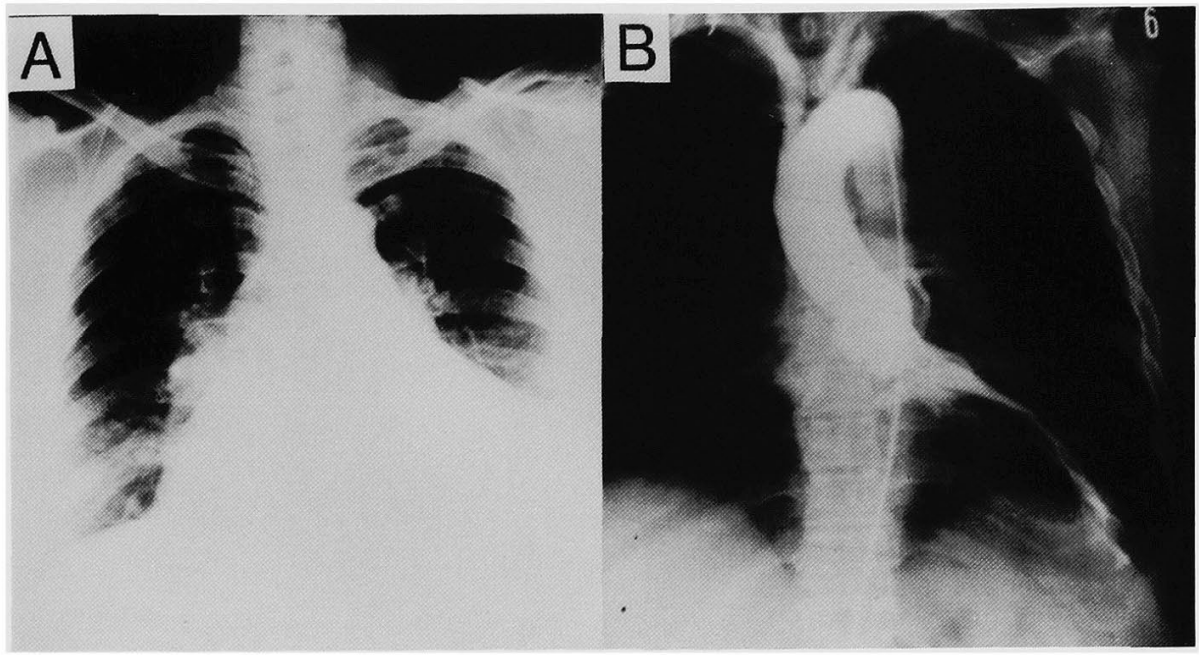

Figure 1. Chest X-ray film (A) and left ventriculogram (B) in 1976. A: Chest X-ray film showed marked cardiomegaly. B: Left ventriculogram showed cavity obstruction at the end-systolic phase.

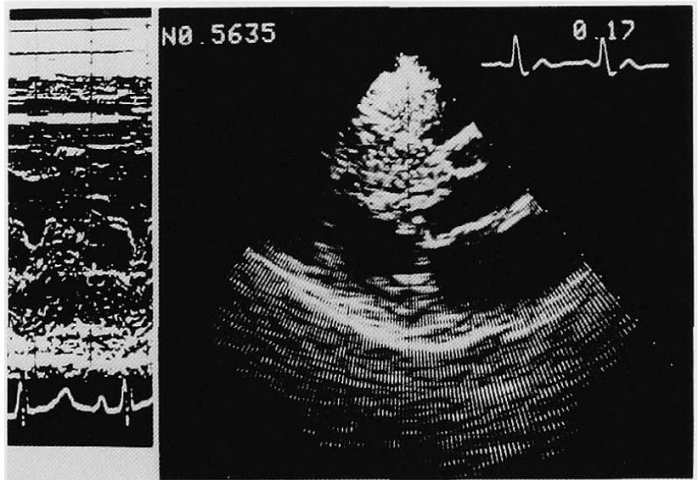

Figure 2. Echocardiogram (parasternal long axis view; M-mode and B-mode). Systolic anterior movement of the anterior mitral leaflet and asymmetrical septal hypertrophy were demonstrated.

$90 \mathrm{mmHg}$, with a mean pressure of $105 \mathrm{mmHg}$. The cardiac index was $2.3 \mathrm{l} / \mathrm{min} / \mathrm{m}^{2}$. Coronary angiogram revealed no obstructive lesions. Left ventriculogram showed obliteration of the left ventricular cavity in the endsystolic phase (Figure 1B).

On April 16, 1979, trans-aortic myectomy of the interventricular septum 


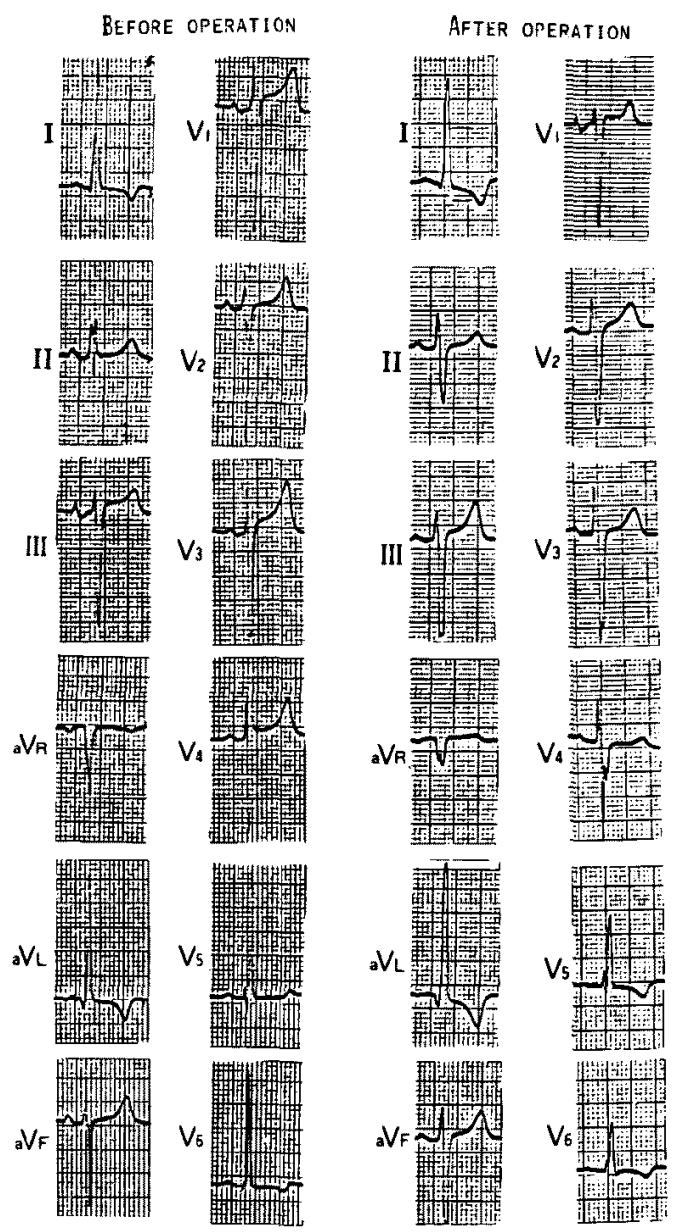

Figure 3. Electrocardiogram before operation (left) and after operation (right). Left electrocardiogram showed left ventricular hypertrophy, left atrial overload, and ST segment depression in $I, a V_{L}, V_{5}$, and $V_{6}$ leads. Right electrocardiogram demonstrated left atrial overload and ST segment depression in $I_{,} a V_{L}, V_{5}$ and $V_{6}$ leads.

was performed. In a postoperative ECG, left axis deviation was present and voltages in $V_{5}$ and $V_{6}$ were decreased compared to the pre-operative ECG (Figure 3). The left ventriculogram demonstrated a slight decrease in the left ventricular cavity (Figure 4A and 4B).

Postoperative catheterization revealed reduction of the interventricular pressure gradient from $98 \mathrm{mmHg}$ to $50 \mathrm{mmHg}$. A coronary angiographic examination two years after surgery showed normal coronary arteries (Figure $4 \mathrm{C}$ and 4 D).

After more than ten admissions because of congestive heart failure and 


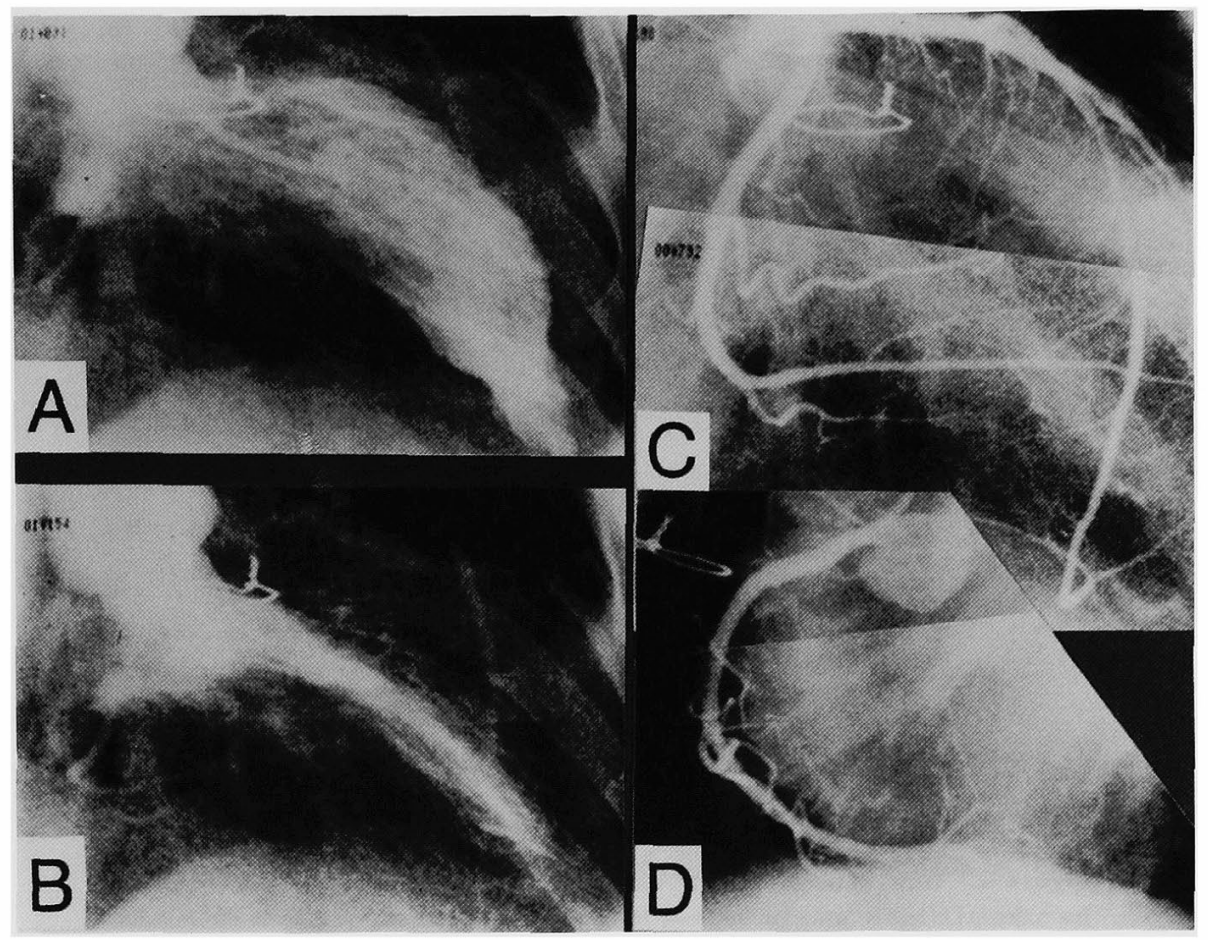

Figure 4. Left ventriculogram [A; end-diastolic phase, B; end-systolic phase and coronary angiogram (C and D)] 2 years after operation. A, B: Left ventricular function slightly improved. C: Left coronary artery was normal. D: Right coronary artery was normal.

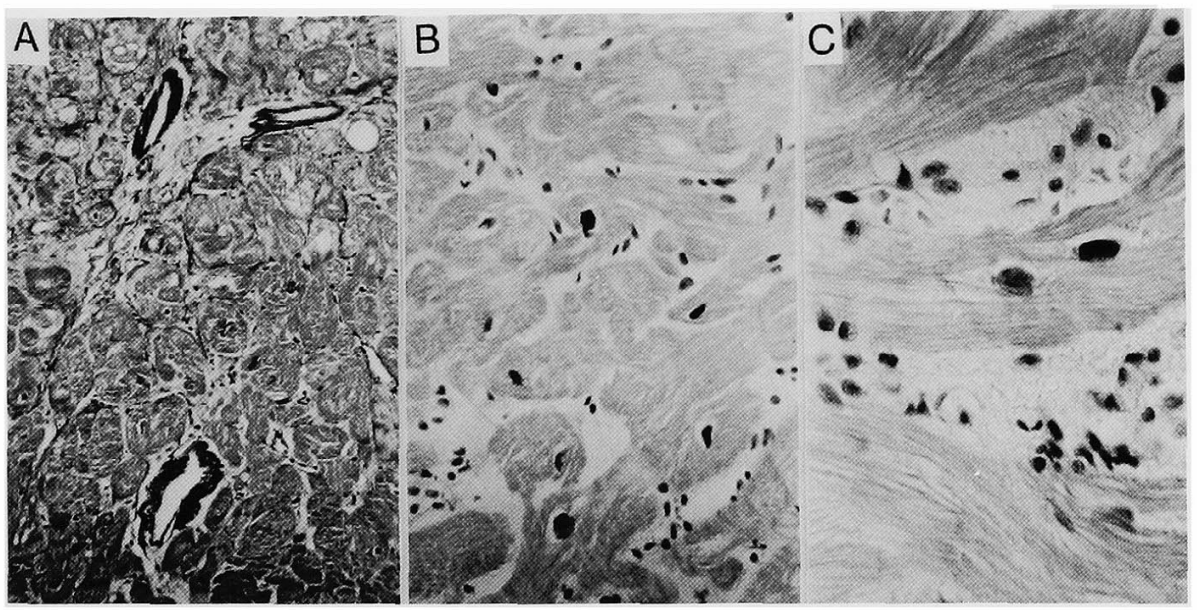

Figure 5. Pathological findings of the resected myocardium. A: Intramural small coronary arteries showed only mild medial thickening (Pentachrome $\times 100$ ). B: Moderate myocardial disarray and interstitial cell infiltration were seen $(\mathrm{H}-\mathrm{E} \times 200)$. C: Interstitial fibrosis and cell infiltration were seen $(\mathrm{H}-\mathrm{E} \times 400)$. 


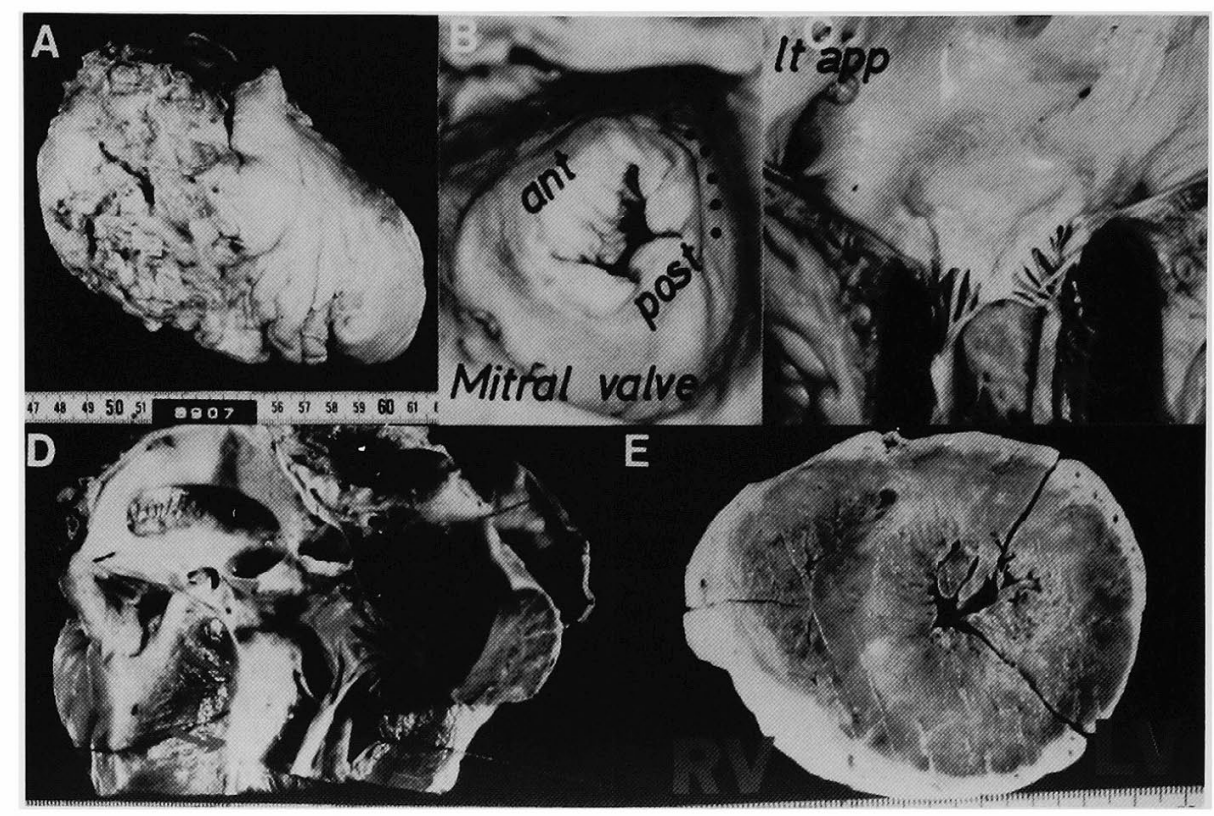

Figure 6. Gross findings of heart (A: anterior view, B: mitral valve, C: left ventricular inflow, D: left ventricular outflow, E: transverse section of ventricle at the middle portion). A: Epicardium was adherent to the heart due to operation. B: Commissure site (...) of posterior mitral leaflet (post) bulged toward the left atrium and anterior mitral leaflet (ant) did not. G: Left mitral leaflet thickened at coaptation. A small mural thrombus was scen near the left appendage (lt app). D: Fibrous thickening was seen at the surgical site in the base of the left ventricular outflow. E: Left ventricle showed marked hypertrophy.

diabetes mellitus the patient died of renal failure in October, 1989.

Pathological findings of the myocardium resected in 1979: Myocardial histology revealed marked endocardial fibroelastic thickening and slight fibrosis in the subendocardial layer. Intramural small coronary arteries did not show sclerotic changes except for mild medial thickening (Figure 5A). Myocardial disarray and a mild amount of cell infiltrations were recognized (Figure $5 \mathrm{~B}$ and $\mathrm{C}$ ).

Gross findings of the heart autopsied in 1989: The heart was enlarged and weighed $660 \mathrm{~g}$. Focal fibrosis of the pericardium due to cardiac surgery was seen on the epicardial adiposis (Figure 6A). The posterior mitral leaflet, near the posterior commissure site, bulged toward the left atrium (Figure 6B). The anterior mitral leaflet was thickened at the coaptation site of the valve (Figure 6C). Focal endocardial fibrous thickening was seen at the operated site of the septum in the base of the left ventricular outflow tract (Figure 6D). In the ventricular transverse section, the left ventricle showed concentric hypertrophy (Figure 6E). The thickness of the interventricular septum was $20-24 \mathrm{~mm}$, and that of the left ventricular 


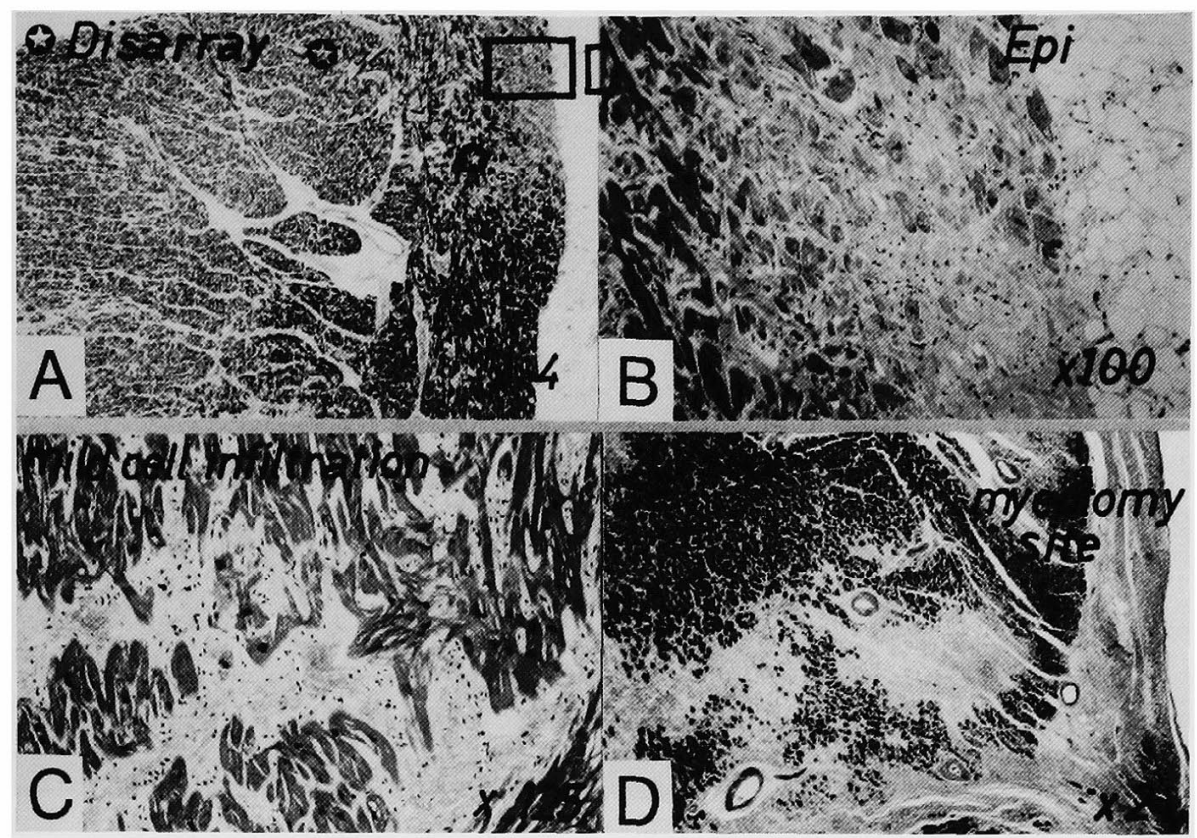

Figure 7. Microscopic findings of heart (A, B and C: lateral wall, D: myectomy site). A: Disarray and fibrosis at the subepicardial site were seen $(A z a n \times 4)$. B: Fibrosis and slight cell infiltration were seen at the subepicardial site (Epi) $(\mathrm{H}-\mathrm{E} \times 100)$. C: Disarray and mild cell infiltration were secn $(\mathrm{H}-\mathrm{E} \times 125)$. D: Fibrosis and mild intramural coronary artery stenosis were seen at the left ventricular septum (LV sept) $(\mathrm{H}-\mathrm{E} \times 2)$.

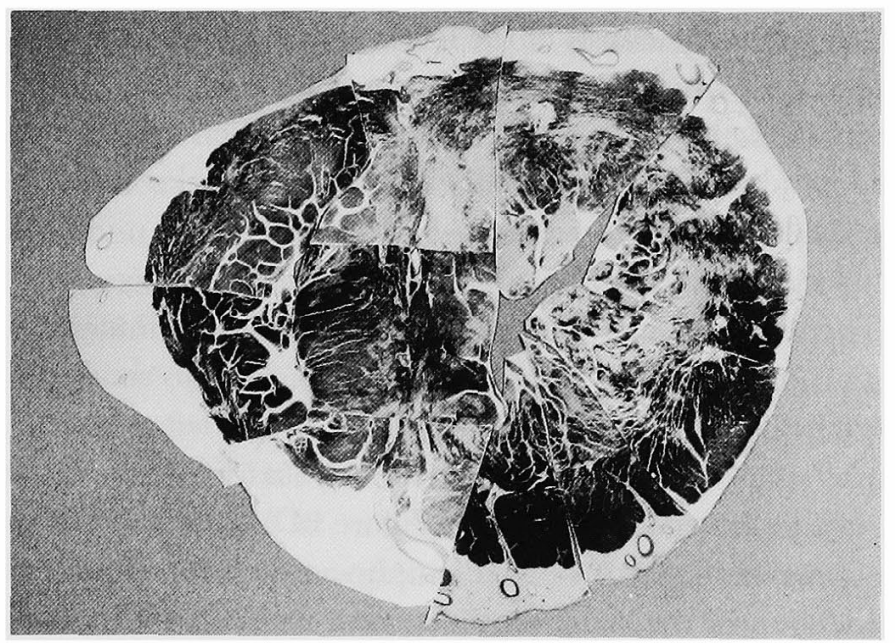

Figure 8. Pathologic finding of transverse section of left ventricle (Azan). Fibrosis was seen mainly in the lateral and posterior wall. 


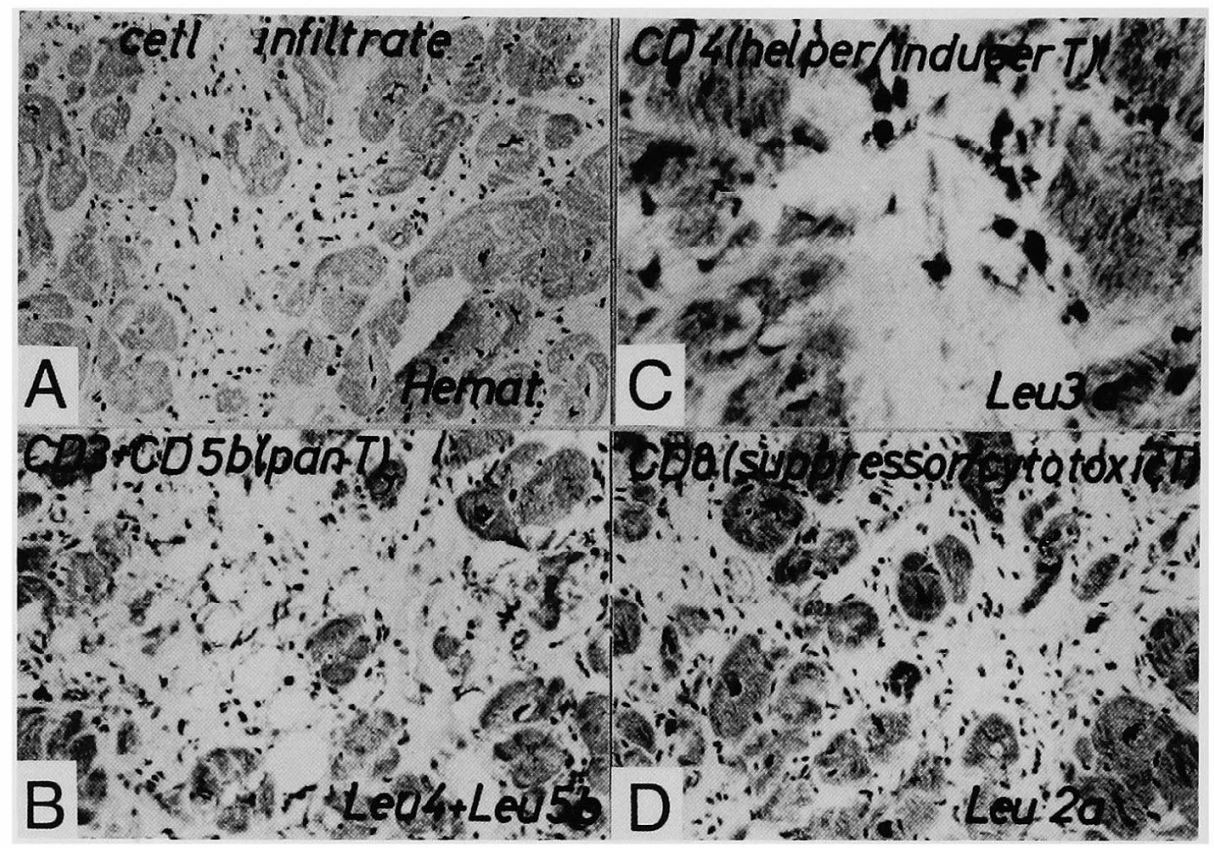

Figure 9. Lymphocyte subsets (A: hematoxylin, B: CD3 and CD5b, C: CD4, D: CD8). A: Cell infiltration was seen $(\times 200)$. B: CD3 positive and CD5b positive cells were seen in the interstitium $(\times 200)$. C: Many CD4 positive cells were seen $(\times 400)$. D: Fewer CD8 positive cells were seen than CD4 positive cells $(\times 200)$.

posterior wall was $18 \mathrm{~mm}$. Fibrosis was seen mostly in the internal layer of the left ventricle, but patchy irregular fibrosis was seen in the middle and outer layers of the posterolateral wall.

There was subtotal stenosis of the left anterior descending branch of the left coronary artery, and 50-75\% stenosis in the left circumflex branch of the left coronary artery and the right coronary artery, respectively. Fibrosis was more severe in the lateral and posterior wall than in the anterior wall (Figure 7).

Microscopic findings of the heart: In the outer and middle layers of the lateral wall of the left ventricle, a moderate degree of myocyte disarray was recognized. The outer layer of the ventricular wall showed interstitial fibrosis and partial depletion of myocytes (Figure $8 \mathrm{~A}$ and $8 \mathrm{~B}$ ). Diffuse small round cell infiltrations were also observed in the myocardium of the left ventricle (Figure 8C). The intramural small arteries ending in the myocardial fibrosis showed medial thickening, but the lumens were patent (Figure 8D).

Lymphocyte subsets (Figure 9): The lymphocyte subsets of the infiltrating cells of the frozen section of the right ventricle were investigated by the ABC (avidin biotin complex) method. Lymphocytes were stained as follows; Leu-4+Leu-5b (CD2+CD5) for pan T cells, Leu-16 (CD20) for B cells, Leu-3a (CD4) for helper/ 
inducer $\mathrm{T}$ cells, and Leu-2a (CD8) for suppressor/cytotoxic $\mathrm{T}$ cells. The positive cells for every stain were counted in 20 field areas microscopically (magnification, $\times 200$ ) and their means were calculated. Mean numbers of these positive lymphocytes per field were 16.3 for pan $\mathrm{T}$ cells, 2.4 for $\mathrm{B}$ cells, 9.2 for helper/inducer $\mathrm{T}$ cells, and 2.4 for suppressor/inducer T cells, respectively. CD4-positive lymphocytes were greater in number than the CD8-positive lymphocytes, and the ratio of CD4 to CD8 was 3.8. Fifty-six percent of the T cells were CD4-positive.

\section{Discussion}

This case had shown interstitial cell infiltration in a biopsy specimen 10 years before death. However, myocardial histology revealed slight fibrosis in the subendocardial layer and the intramural small coronary arteries did not show sclerotic changes except for mild medial thickening. At autopsy, cell infiltration remained and fibrosis was secn in the middlc and outer layers of the postcrolateral wall. Myocardial fibrosis was seen not only in the subendocardium, but also in the subepicardium. The fibrosis was not consistent with coronary stenosis, since the anterior interventricular coronary artery had subtotal stenosis, but fibrosis was seen in the posterolateral wall, which was supplied by the right coronary artery and left circumflex artery. Although a part of the fibrosis was caused by coronary artery stenosis, it could not be explained merely by ischemia, because fibrosis was seen not only in the subendocardium, but also in the subepicardium.

The causes of myocardial fibrosis in HCM, and the transformation of HCM to DCM have been reported as follows: organic stenosis or functional spasm of the intramural small vessels, ${ }^{14)}$ the obstruction of main coronary arteries due to thrombus or spasm, ${ }^{14)}$ relative shortness of coronary flow associated with myocardial hypertrophy, ${ }^{14)}$ decreased vasodilator reserve ${ }^{15)}$ myocarditis ${ }^{8)}$ surgery ${ }^{16)}$ and long-term administration of beta-blocker. ${ }^{17}$ )

Cell infiltration in HCM was demonstrated to be for the purpose of phagocytosis of degenerating cardiac myocytes. ") Yutani et al suggested that cell infiltration may be related to fibrosis in HCM. ${ }^{18)}$ Moreover, it was reported that the heart of a patient with myocarditis in childhood showed gradually increasing left ventricular hypertrophy that was confused with HCM. ${ }^{19)}$ However, a precise study of infiltrated cells in HCM has not been reported.

Several investigations of cell infiltration and lymphocyte subsets in myocarditis and dilated cardiomyopathy from endomyocardial biopsy specimens have been reported. ${ }^{20-26)}$ These authors reported that CD8-positive T lymphocytes increased. The GD4/CD8 ratio was $0.3-0.6$ and changed during the healing process in acute myocarditis. In dilated cardiomyopathy, $50 \%$ of infiltrating 
cells consisted of macrophages, $30 \%$ were $\mathrm{T}$ lymphocytes, and about half of the T lymphocytes were CD8 positive. In this case, CD4/CD8 was 3.8 and $56 \%$ of the $\mathrm{T}$ cells were CD4-positive cells. These values were different from those seen in myocarditis and dilated cardiomyopathy. It was not clear whether or not this result was specific for infiltrating cells in HCM.

Considering that the main infiltrating $\mathrm{T}$ cells in the skin lesions of Kawasaki's disease are CD4, and those in the skin lesions of measles are CD8, ${ }^{27)}$ the ratio of CD4/CD8 in this case does not imply viral infection. However, cell infiltration in HCM should be studied further.

\section{REFERENCES}

1. Silver MD: Cardiovascular Pathology. 2nd ed, Churchill Livingston, New York, p743, 1991

2. St John Suton MG, Lie JT, Anderson KR, Frye RL: Histopathological specificity of hypertrophic obstructive cardiomyopathy; myocardial fibre disarray and myocardial fibrosis. Br Heart J 44: 433, 1980

3. Tanaka M, Fujiwara H, Onodera T, Wu D-J, Hamashima Y, Kawai C: Quantitative analysis of myocardial fibrosis in normal, hypertensive hearts, and hypertrophic cardiomyopathy. Br Heart J 55: 575,1986

4. Waller BF, Maron BJ, Epstein SE, Roberts WC: Transmural myocardial infarction in hypertrophic cardiomyopathy; a case of conversion from left ventricular asymmetry to symmetry and from normalsized to dilated left ventricular cavity. Chest 79: 461, 1981

5. ten-Cate FJ, Roelandt J: Progression to left ventricular dilatation in patients with hypertrophic obstructive cardiomyopathy. Am Heart J 97: 762, 1979

6. Beder SD, Gutgesell HP, Mullins CE, McNamara DC: Progression from hypertrophic obstructive cardiomyopathy to congestive cardiomyopathy in a child. Am Heart J 104: 155, 1982

7. Fujiwara H, Onodera T, Tanaka M, Shirane H, Kato H, Yoshikawa J, Osakada G, Sasayama S, Kawai C: Progression from hypertrophic obstructive cardiomyopathy to typical dilated cardiomyopathy-like features in the end stage. Jpn Circ J 48: 1210, 1984

8. Yutani C, Imakita M, Ishibashi-Ueda H, Hatanaka K, Nagata S, Sakakibara H, Nimura Y: Three autopsy cases of progression to left ventricular dilatation in patients with hypertrophic cardiomyopathy. Am Heart J 109: 545, 1985

9. Funakoshi M, Imamura M, Sasaki J, Fujino M, Kawano T, Sasaki Y, Nakashima Y, Motooka T, Keisuke F, Imagawa M, Hiroki T, Arakawa K: Seven year follow-up of a patient with hypertrophic cardiomyopathy which progressed to dilated cardiomyopathy. Jpn Heart J 25: 805, 1984

10. Onodera T, Fujiwara H, Tanaka M, Wu DJ, Hamashima Y, Kawai C: Familiar hypertrophic cardiomyopathy mimicing typical dilated cardiomyopathy. Jpn Circ J 50: 614, 1986

11. Hirota Y, Shimizu M, Sugihara N, Suematsu T, Shibayama S, Itoh H, Takeda R, Terada T: An autopsy case of hypertrophic cardiomyopathy showing dilated cardiomyopathy-like features by serial ventriculography. Jpn J Med 29: 448, 1990

12. Becker AE, Anderson RH: Cardiac Pathology. Gower Medical Publishing, London, p3, 1982

13. Fujiwara H, Kawai C: Intramural coronary artery disease in hypertrophic cardiomyopathy. in Cardiomyopathy Update 2. Hypertrophic Cardiomyopathy. ed by Toshima $\mathbf{H}$, Maron BJ, University of Tokyo Press, Tokyo, p 47, 1988

14. Maron BJ, Epstein SE, Roberts WC: Hypertrophic cardiomyopathy and transmural myocardial infarction without significant atherosclerosis of the extramural coronary arteries. Am J Cardiol 43: 1086, 1979

15. Cannon RO, Rosing DR, Maron BJ, Leon MB, Bonow RO, Watson RM, Epstein SE: Myocardial ischemia in patients with hypertrophic cardiomyopathy; contribution of inadequate vasodilator reserve and elevated left ventricular filling pressure. Circulation 71: 234, 1985 
16. Turina J, Jenni R, Krayenbuehl HP, Turina M, Rothlin M: Echocardiographic findings late after myectomy in hypertrophic obstructive cardiomyopathy. Eur Heart J 7: 685, 1986

17. Mckenna WJ, Borggrefe M, England D, Deanfeld J, Oakley CM, Goodwin JF: The natural history of left ventricular hypertrophy in hypertrophic cardiomyopathy; an electrocardiographic study. Circulation 66: 1233,1982

18. Yutani G, Imakita M, Ishibashi-Ueda H, Nagata S, Sakakibara H, Nimura Y: Histopathological study of hypertrophic cardiomyopathy with progression to left ventricular dilatation. Acta Pathol Jpn 37: 1041,1987

19. Okuni M, Yamada T, Mochizuki S, Sakurai I: Studies on myocarditis in childhood, with special reference to the possible role of immunological process and thymus in the chronicity of the disease. Jpn Circ J 39: 463,1974

20. Kishimoto C, Tomioka N, Tamaki S, and Kawai C: A case of myocarditis with immunological identification of myocardial and peripheral lymphocyte subsets. Jpn Circ J 52: 94, 1988

21. Cassling RS, Linder J, Sears TD, Waller BF, Rogler WC, Wilson JE, Kugler JD, Kay DH, Dillon JC, Slack JD, and McManus BM: Quantitative evaluation of inflammation in biopsy specimens from idiopathically failing or irritable hearts; experience in 80 pediatric and adult patients. Am Heart J 110: 713,1985

22. Zee-Chung CS, Tsai CG: High incidence of myocarditis by endomyocardial biopsy in patients with idiopathic congestive cardiomegaly. J Am Coll Cardiol 3: 63, 1984

23. Marboe CC, Knowles DM: Characterization of the inflarmmatory infiltrate in human myocarditis: An endomyocardial biopsy study, in Viral Heart Disease, ed by Bolte HD, Springer, New York, p64, 1984

24. Kueul U, Toussaint M, Ulrich G, Wagner D, Wolff P, Schultheiss HP: Evaluation of immunohistological data for the diagnosis of myocarditis. in New Concepts in Viral Heart Disease, ed by Schutheiss HP, Springer, New York, p 325, 1988

25. Saito T, Shiokawa A, Inoue $S$ : Lymphocytic subpopulations and their transition in myocardial tissue and peripheral blood of patients with biopsy proven myocarditis. Jpn Circ J 53: 1, 1989

26. Hammond $\mathrm{EH}$, Anderson JL: Cardiac immune complex and mononuclear cell subsets in myocarditis; an endomyocardial biopsy study. Circulation 68 (Suppl III): 27, 1983

27. Sugawara T, Hattori S, Hirose S, Furukawa S, Yabuta K, Shirai T: Immunopathology of the skin lesion of Kawasaki disease. in Kawasaki Disease, ed by Shulman ST, Alan R. Liss, Inc., New York, p 185, 1987 